\title{
Somogy megye tegzeseinek (Trichoptera) jegyzéke
}

ty.

\author{
NÓGRÁdi SÁRA És UHERKOVICH ÁKOS
}

NóGRÁDI, S. \& Á. UHERKOVICH: Checklist of the caddisflies (Trichoptera) of Somogy county, Hungary. Abstract: 123 species belonging to 16 families have been collected in the county until recently. The bulk of the faunistical studies was carried out during the 80's and 90's. Four species of the Hungarian fauna have been reported only in this county so far: Hydroptila pulchricomis (Pictet, 1834), Micrasema setiferum (Pictet, 1834), Silo piceus (Brauer, 1857) and Helicopsyche bacescui Orghidan \& Botosaneanu, 1953.

\section{Bevezetés}

A Fauna Regni Hungariae a „történelmi” Magyarország területéról az akkori rendszerezés szerinti 7 tegzes család 140 faját említi meg. Csak 65 faj név szerinti lelóhelyét adja meg az ország jelenlegi területére, a többinél nem ad meg konkrét elófordulási adatot, vagy a ma már környező országokhoz tartozó hegyvidéki lelóhelyeket említ (MOCSÁRY 1900).

A fenti idézett munka csak 8 fajt közöl 3 somogyi (Balaton-parti) lelóhelyról.

Somogy megye természettudományos kutatása az elmúlt két évtizedben vált intenzívvé. A század elsô felében és még az ötvenes, hatvanas években is csak elszigetelt próbálkozások történtek egy-két állatcsoport viszonyainak feltárására.

Ez különösen vonatkozik a tegzesekre, amelyeknek mind gyújtése, mind pedig feldolgozása nagyobb felkészülést és gyakorlatot feltételezó munka. A Fauna Regni Hungariae adatait követóen hetven éven keresztül nem gyarapodtak ismereteink Somogyról. A hatvanas, hetvenes években megjelenó csekély számú, tegzesekkel foglalkozó hazai munka között csak egy olyan akadt, amely további 3 faj elófordulását említi a megyéból (UjHELYI 1971). A hatvanas és a hetvenes években a budapesti Magyar Természettudományi Múzeum gyưijteményében ugyan tettek el további tegzeseket, azonban ezek feldolgozása csak alig több mint tíz éve történt meg (NóGráDI 1989).

A rendszeres kutatások kezdete Ujhelyi Sándor nevéhez fúződik, aki a Barcsi borókásban (Barcsi Tájvédelmi Körzetben) elsôsorban fénycsapdával gyújtött anyagokat dolgozott fel (UjHeLY 1981). I 982-tól jelen cikk szerzói ugyanott folytatták az intenzív fauna-feltárást, majd Somogy egyéb részein is jelentôsebb gyújtőtevékenységet végeztek és végeznek napjainkban is. Somogy megye számos kistáját vizsgálták és azokról publikációkat készítettek: Dráva mente (Szentborbás, Barcs, Babócsa, Heresznye, Vízvár, Bélavár, Somogyudvarhely, Zákány, Órtilos); Barcsi Tájvédelmi Körzet; Baláta-tó és környéke; Zselic és a Zselici Tájvédelmi Körzet (Lipótfa, Ropolypuszta, Kaposfó, Sántos); Boronka-melléki Tájvédelmi Körzet; Balaton déli partja és a befolyó vizek; Belső-Somogy egyéb vidékei. Fajokban a leggazdagabb lelơhely- 
nek Örtilos bizonyult, ahonnét 67 fajt ismerhettünk meg. A megjelent publikációkat az irodalomjegyzék tartalmazza, ezekre egyes fajok előfordulásával kapcsolatban hivatkozunk.

Napjainkra 16 családba tartozó 123 Trichoptera fajt ismerünk Somogy megye területéról. Tehát az összes hazai faj (209) 58,9 \%-a fordul elő itt. 3 további család képviselôi nem fordulnak elô Somogyban.

A fajok közül ki kell emelnünk négyet, amelyeknek Magyarországon mindezidáig csak Somogyban van bizonyított előfordulási helyük. A Micrasema setiferum (Pictet, 1834) egyetlen példányát fogtuk még 1983. május 4-én a Barcsi Tájvédelmi Körzetben (NóGRÁDI 1985a). Bár ott is sokat gyújtöttünk azóta, újabb példány nem került elô sem itt, sem másutt az országban. A legutóbbi években találtuk meg a Hydroptila pulchricornis (Pictet, 1834) elsố hazai példányát a már addig is intenzíven vizsgált Barcsi TK-ben, a Helicopsyche bacescui Orghidan \& Botosaneanu, 1953 somogyudvarhelyi populációjának megtalálása pedig az utóbbi évtized egyik legfontosabb trichopterológiai felfedezése volt, mivel a rendkívül kis elterjedési területú fajnak ez egy távoli, sérülékeny, de egyedekben egyelóre viszonylag gazdag populációja. (Sajnos, idóközben az élóhelyet súlyosan károsították.) A Silo piceus Brau. fajt korábban ugyan már máshonnét is említették Magyarországról, azonban az általunk látott $s$ ennek a fajnak határozott példányok mind Silo pallipes Fabr.-nak bizonyultak. Hiteles Silo piceus Brau. csak a Drávában él, eddig Ốrtiloson és Vízváron találtuk.

Természetvédelmi szempontból rendkívül jelentôs a Dráva somogyi szakasza. A folyó fố folyásában és a hozzá csatlakozó vizek somogyi szakaszán több mint száz tegzes faj fordul eló. Itt él a Platyphylax frauenfeldi Brau. utolsó, még stabil populációja, ez minden bizonnyal a Dráva gyorsan folyó vizében, a fớmederben fejlődik. Más európai lelóhelyeiról már egy évszázada eltúnt.

Ugyancsak sok érdekességet rejtenek a somogyi lápvidékek. Számos érdekes faj kisebb-nagyobb populációit fedeztük fel ezekben, például Limnephilus subcentralis Brau., Limnephilus stigma Curt., Limnephilus elegans Curt., Anabolia brevipennis Curt. vagy Erotesis baltica McL.

\title{
A Somogy megyében előforduló fajok jegyzéke
}

A korábbi munkákban szereplő rendszert és nevezéktant használjuk. Az egyes fajok után szögletes zárójelben adjuk meg azokat az irodalmi forrásokat, amelyek somogyi előfordulási adatokat közölnek. A közöletlen adatok száma viszonylag csekély, ezeket a lelóhelyeket - csak a település nevével kiírva - az irodalmi hivatkozások után megadjuk.

\author{
*** Védett faj \\ [ $1 \ldots 23]$ irodalmi hivatkozás
}




\section{Rhyacophilidae}

Rhyacophila dorsalis (Curtis, 1834) - $[8,14,15]$

Rhyacophila fasciata Hagen, 1859 - [11]

\section{Glossosomatidae}

Glossosoma boltoni Curtis, 1834 - [14]

Agapetus delicatulus McLachlan, $1884-[2$,

$4,13,14,17]$

Agapetus laniger (Pictet, 1834) - $[2,14,17]$

\section{Hydroptilidae}

Orthotrichia angustella (McLachlan, 1865) -

$[13,14,15]$

Orthotrichia costalis (Curtis, 1834) - [2, 11,

12, 13, 14, 15, 17, 19], Gyékényes

Orthotrichia tragetti Mosely, $1930-[2,3$,

$11,12,13,14,15,17,19]$ Ithytrichia lamellaris Eaton, $1873-[2,12$,

13, 14, 17, 19]

Oxyethira falcata Morton, $1893-[2,11,12$,

$13,14,15,17]$

Oxyethira flavicornis (Pictet, 1834) $-[2,3,8$,

12, 13, 14, 15, 17], Gyékényes

Hydroptila angustata Mosely, $1939-[2,13$,

14, 19]

Hydroptila dampfi Ulmer, $1929-[4,11,12$,

$13,14,211$

Hydroptila forcipata (Eaton, 1873) - [11,

14,15

Hydroptila lotensis Mosely, 1930 - $[13,14]$ Hydroptila occulta (Eaton, 1873) - $[2,14,17]$ Hydroptila pulchricornis (Pictet, 1834) - [15] 17) Hydroptila simulans Mosely, $1920-[4,11$,

Hydroptila sparsa Curtis, $1834-[2,11,12$,

13, 14, 15, 17], Látrány

Hydroptila vectis Curtis, $1834-[12,13,12]$

Agraylea sexmaculata Curtis, $1834-[2,9$,

$11,12,13,14,15,17,19]$

Hydropsychidae

Hydropsyche angustipennis Curtis, 1834 -

[1 1, 12, 13, 14, 15, 17], Kisberény, Látrány Hydropsyche bulbifera McLachlan, 1878 -

$[11,12,13,14,15,17]$

Hydropsyche bulgaromanorum Malicky, 1977 -

$[2,6,11,12,13,14,15,17,19]$, Gyékényes,

Középrigóc (Barcs), Látrány

Hydropsyche contubernalis McLachlan, 1865 -

$[2,6,9,11,12,13,14,15,17,19,23]$,

Kisberény, Látrány, Zselickisfalud, Zselicszentpál Hydropsyche modesta Navás, $1925-[2,9$, 11, 12, 13, 14, 15, 17, 19], Középrigóc (Barcs), Látrány
Hydropsyche ornatula McLachlan, $1878-[2$,

$9,11,12,13,14,15,17,19,23]$

Hydropsyche pellucidula (Curtis, 1834) - $[2$,

$11,12,13,14,15,17,19,23$ ]

Hydropsyche saxonica McLachlan, $1884-[6$,

11, 12, 13, 15, 17], Látrány

\section{Polycentropodidae}

Neureclipsis bimaculata (Linnaeus, 1758) -

$[2,9,11,12,13,14,15,17,19,23]$

Plectrocnemia conspersa (Curtis, 1834) - [11,

13, 14, 15, 21], Kisberény, Látrány,

Zselickisfalud

Polycentropus flavomaculatus (Pictet, 1834) -

$[13,17]$

Holocentropus dubius (Rambur, 1842) - [13,

$14,15,19,21]$

Holocentropus picicomis (Stephens, 1836) -

$[2,11,12,13,14,15,17,19]$

Holocentropus stagnalis (Albarda, 1874) $-[2$,

$6,13,14,15,17,21]$

Cyrnus crenaticornis (Kolenati, 1859) $-[2$,

1 1, 12, 13, 14, 15, 17, 19], Középrigóc (Barcs)

[5, 19]

Cyrnus trimaculatus (Curtis, 1834) - [14,

\section{Psychomyidae}

Psychomyia pusilla (Fabricius, 1781) - [2, 9,

11, 12, 13, 14, 15, 17, 19], Középrigóc (Barcs) Lype phaeopa (Stephens, 1836) - [11, 13,

$14,15,19]$

Lype reducta (Hagen, 1868) - $[11,12,13$,

14, 15, 19, 21], Kisberény

Tinodes pallidulus McLachlan, 1878 - [2],

[17], Komlósd

\section{Ecnomidae}

Ecnomus tenellus (Rambur, 1842) - $[2,6,9$, 11, 12, 13, 14, 15, 17, 19], Látrány

\section{Phryganeidae}

Trichostegia minor (Curtis, 1834) - [2, 9, 11, $12,13,14,15,17,21,23]$

Agrypnia pagetana Curtis, $1835-[11,13,17]$ Agrypnia varia (Fabricius, 1793) - [1, 2, 6,

$9,11,12,13,14,15,17,23]$, Gyékényes

Phryganea bipunctata Retzius, 1783 -

Bélavár

Phryganea grandis Linnaeus, 1758 - [1, 2, 6,

$9,11,12,13,14,15,17,19]$, Bélavár,

Középrigóc (Barcs), Zselickisfalud Hagenella clathrata (Kolenati, 1848) $-[2$,

11, 14, 15, 17], Látrány

Oligostomis reticulata (Linnaeus, 1761) - [6,

11, 12, 13, 15, 17], Kisberény, Látrány 


\section{Brachycentridae}

Brachycentrus subnubilus Curtis, $1834-[8$,

$11,14,15,17]$

Micrasema setiferum (Pictet, 1834) $-[2,3$,

17,181

\section{Limnephilidae}

Ironoquia dubia (Stephens, 1837) - $[2,11$, $12,13,14,15,17,23]$

Limnephilus affinis Curtis, $1834-[1,2,6,9$,

11, 12, 13, 14, 15, 17, 19, 23], Gyćkényes,

Látrány, Maggyaregres, Zselickisfalud, Zselicszentpál

Limnephilus auricula Curtis, $1834-[2,6,9$,

11, 12, 13, 14, 15, 17], Zselickisfalud

Limnephilus binotatus Curtis, $1834-[12$,

13, 15, 17], Középrigóc (Barcs)

Limnephilus bipunctatus Curtis, $1834-[1,2$,

$6,11,12,13,14,15,17,19]$, Középrigóc

(Barcs), Zselickisfalud

Limnephilus decipiens (Kolcnati, 1848) $-[2$,

$6,11,12,13,14,171$

Limnephilus elegans Curtis, $1834^{* * *}-[5,8$,

11,161

Limnephilus extricatus McLachlan, 1865 -

[2, 11, 12, 13, 14, 15, 17], Látrány

Limnephilus flavicornis (Fabricius, 1787) -

$[1,2,6,9,11,12,13,14,15,17,19,23]$,

Kisberény, Látrány, Magyaregres, Vízvár Limnephilus griseus (Linnacus, 1758) - [1, 2,

$6,11,12,13,14,15,17,19,23]$, Látrány

Limnephilus hirsutus (Pictet, 1834) $-[2,11$,

13, 14, 17]

Limnephilus ignarus McLachlan, I $865-[2$,

11, 12, 14, 17]

Limnephilus (Colpotaulius) incisus Curtis,

1834-[1, 6, 1 1, 12, 13, 14, 15], Látrány

Limnephilus lunatus Curtis, $1834-[2,6,9$,

11, 12, 13, 14, 15, 17, 19, 23], Gyékényes, Látrány

Limnephilus nigriceps (Zetterstedt, 1840) -

$[6,13,17]$

Limnephilus rhombicus Linnaeus, $1758-[2$,

$6,11,12,13,14,15,17,23]$, Látrány

Limnephilus sparsus Curtis, $1834-[2,9,11$,

$12,13,14,17$

Limnephilus stigma Curtis, 1834 - [10, 15]

Limnephilus subcentralis Brauer, $1857-[7$,

$12,13,14,16,18]$

Limnephilus vittatus (Fabricius, 1798) $-[1$,

2, 6, 11, 12, 13, 14, 15, 17, 19], Középrigóc

(Barcs), Órtilos

Grammotaulius nigropunctatus (Retzius, 1783) - $[2,6,9,11,12,13,14,15,17,19,23]$, Látrány, Magyaregres, Örtilos, Zselickisfalud
Grammotaulius nitidus (Müller, 1764) - [13]

Glyphotaelius pellucidus (Retzius, 1783) - [2,

$9,11,12,13,14,15,17,19,23]$, Látrány,

Magyaregres, Zselickisfalud

Anabolia brevipennis (Curtis, 1834) - [11,

12, 13, 14, 15. 16, 21], Látrány

Anabolia furcata Brauer, 1857 - [11, 12, 13,

14, 15, 17, 19]

Rhadicoleptus alpestris (Kolenati, 1848) -

$[11,14,15]$

Potamophylax nigricomis (Pictet, 1834) - [11]

Potamophylax rotundipennis (Brauer, 1857) -

โ11, 12, 13, 14, 15, 17\}, Középrigóc (Barcs)

Halesus tesselatus (Rambur, 1842) $-[2,11$,

12, 13, 14, 15, 17, 19, 23], Látrány

Platyphylax frauenfeldi (Brauer, 1857) ***

$[2,5,8,9,11,14,15,17,19,20,23]$

Stenophylax meridiorientalis Malicky, 1980 -

[11], Zselicszentpál

Stenophylax permistus McLachlan, 1895 - [2,

$6,9,11,12,13,14,15,17,19,23]$, Kisberény,

Látrány, Zselickisfalud, Zselicszentpál

Micropterna lateralis (Stephens, 1837)-[11,

14,17

Chaetopteryx fusca Brauer, 1857 - $[13,14]$

Chaetopteryx major McLachlan, 1876 - [1 1,

$12,13,14,15,17]$

\section{Goeridae}

Goera pilosa (Fabricius, 1775) $-[2,9,11$,

$12,13,14,15,17,19]$

Lithax obscurus (Hagen, 1859) - [1 1, 12, 13,

15], Kisberény

Silo piceus (Brauer, 1857) - [8, I4], Vízvár Silo nigricornis (Pictet, 1834) - Vízvár

\section{Lepidostomatidae}

Crunoecia irrorata (Curtis, 1834) - $[11,14$,

$15,21]$

Lasiocephala basalis (Kolenati, 1848) - [11]

\section{Leptoceridae}

Athripsodes albifrons (Linnaeus, 1758) - $[8,14]$ Athripsodes aterrimus (Stephens, 1836) - $[2$,

$6,9,11,12,13,14,15,17,19]$, Kisberény

Athripsodes cinereus (Curtis, 1834) - $[6,13$,

$14,15]$

Ceraclea alboguttata (Hagen, 1860) - [2, 11 ,

12, 13, 14, 15, 17, 19], Középrigóc (Barcs)

Ceraclea annulicomis (Stephens, 1836) - [2,

$11,12,13,14,15,17,19]$

Ceraclea aurea (l'ictet, 1834) - [2, 11, 12,

13, 14, 15, 17, 19, 23]

Ceraclea dissimilis (Stephens, 1836) $-[2,6$,

$9,11,12,13,14,15,17,19,20,22,23]$, Látrány 
Ceraclea fulva (Rambur, 1842) - [11, 13]

Ceraclea riparia (Albarda, 1874) $-[2,13$,

14, 17, 23\}, Látrány

Ceraclea senilis (Burmeister, 1839) - $[2,11$,

12, 14, 15, 17], Középrigóc (Barcs), Látrány

Mystacides azurea (Linnaeus, 1761) - $\lfloor$ 14, 15 Mystacides longicornis (Linnaeus, 1758) $-[2$,

6, 11, 12, 13, 14, 17, 23], Látrány

Mystacides nigra (Linnaeus, 1758) - $[2,11$,

$12,13,14,15,171$

Triaenodes bicolor (Curtis, 1834) - $[2,11$,

12, 13, 14, 15, 17], Középrigóc (Barcs)

Triaenodes kawraiskii Martynov, $1909-[2$,

$9,14,17,23]$

Triaenodes simulans Tjeder, $1929-$ [15]

Erotesis baltica McLachlan, $1877-[8,12,13]$

Oecetis furva (Rambur, 1842) - $[2,6,11$,

$12,13,14,15,17,19,231$, Gyékényes,

Középrigóc (Barcs)

Oecetis lacustris (Pictet, 1834) - $[2,9,11$,

12, 13, 14, 15, 17, 19, 22], Középrigóc (Barcs),

Látrány

Oecetis notata (Rambur, 1842) - [2, 11, 12,

13, 14, 15, 17, 19, 23], Látrány

Oecetis ochracea (Curtis, 1825) - $[2,6,11$,

12, 13, 14, 15, 17, 19, 23], Látrány, Zselicszentpál
Oecetis tripunctata (Fabricius, 1793) $-[2$, $14,15]$

Setodes punctatus (Fabricius, 1793) $-[2,6$, 11, 12, 13, 14, 15, 17, 19], Gyékényes, Középrigóc (Barcs)

Serodes viridis (Fourcroy, 1785) - Órtilos

Leptocerus tineiformis Curtis, $1834-[2,6$, 11, 12, 13, 14, 15, 17, 19, 22, 23], Látrány

Adicella balcanica Botosaneanu et Novák, $1965-[10,15]$

Adicella syriaca Ulmer, 1907 - Vízvár

\section{Sericostomatidae}

Notidobia ciliaris (Linnaeus, 1761) - [11, 12, 13, 15], Látrány

\section{Beraeidae}

Beraea pullata (Curtis, 1834) - $[11,12,13$, 21], Látrány

Beraeodes minutus (Linnaeus, 1761) $-[4,11$, $12,13]$

Ernodes articularis (Pictet, 1834) $-[15,21]$

Helicopsychidae

Helicopsyche bacescui Orghidan \& Botosaneanu, $1953-[10,15,21]$

1. táblázat. A Somogy megyéból eddig kimutatott tegzesek fajszáma, családonként Table 1. The number of species collected in Somogy County, in families.

\begin{tabular}{|l|c|c|}
\hline Család & Fajszám Somogyban & Magyarországi fajszám \\
\hline Rhyacophylidae & 2 & 10 \\
\hline Glossosomatidae & 3 & 10 \\
\hline Hydroptilidae & 15 & 21 \\
\hline (Philopotamidae) & 0 & 4 \\
\hline Hydropsychidae & 8 & 14 \\
\hline Polycentropodidae & 8 & 14 \\
\hline Psychomiidae & 4 & 7 \\
\hline Ecnomidae & 1 & 1 \\
\hline Phryganeidae & 7 & 8 \\
\hline Brachycentridae & 2 & 2 \\
\hline (Apataniidae) & 0 & 1 \\
\hline Limnephilidae & 35 & 59 \\
\hline Goeridae & 4 & 6 \\
\hline Lepidostomatidae & 2 & 4 \\
\hline Leptoceridae & 27 & 36 \\
\hline Sericostomatidae & 1 & 4 \\
\hline Beraeidae & 3 & 5 \\
\hline Helicopsychidae & 1 & 1 \\
\hline (Odontoceridae) & 0 & 1 \\
\hline Összesen & 123 & 209 \\
\hline
\end{tabular}




\section{Irodalom}

[1] MocsírY, S. 1900: Ordo Neuroptera. In: A Magyar Birodalom Állatvilága. Fauna Regni Hungariac. - Budapest, p. 33-41.

[2] NóGRÁd, S. 1985a: Caddisflies of the Barcs Juniper Woodland, Hungary (Trichoptera). Dunántúli Dolgozatok Természetudományi Sorozat (Pécs) 5: 117-134.

[3] NÓGRÁDI, S. 1985b: Further caddisfly species new to the Hungarian fauna (Trichoptera). Folia ent. hung. $46(1)$ : 129-135.

[4] NóGRÁDI, S. 1986: New data to the caddisfly fauna of Hungary (Trichoptera). Folia ent. hung. $47(1-2): 135-140$.

[5] NóGrÁDı, S. 1988: New data to the caddisfly (Trichoptera) fauna of Hungary, II. Folia ent. hung. 49: 205-210.

[6] NÓGRÁDI, S. 1989: Locality data of the Trichoptera collection originating from the Carpathian Basin in the Hungarian Natural History Museum. Folia ent. hung. 50: 147-156.

[7] NóGrÁDI, S. 1992: Five Trichoptera species new to the Hungarian fauna. Folia ent. hung. 52 (1991): 181-185.

[8] NóGRÁDI, S. 1994: New data to the caddisfly (Trichoptera) fauna of Hungary, III. Folia ent. hung. 55: 271-280.

[9] NóGRÁDI, S. 1995: Hungarian locality data of Ujhelyi's Trichoptera collection in the Hungarian Natural History Museum. Folia ent. hung. 56: 119-131.

[10] NóGRÁDI, S. 1998: New data to the caddisfly (Trichoptera) fauna of Hungary, IV. Folia ent. hung. 59: 73-78.

[11] Nógrńd, S., Uherkovich, Á. 1990: The Trichoptera fauna of the Zselic Downs, Hungary. A Janus P’annonius Múz. Évk. 34 (1989): 15-38.

[12] Nógirádı S., Uherkovich Á. 1992: A Boronka-melléki Tájvédelmi Körzet és környéke tegzes (Trichoptera) faunája. Dunántúli Dolgozatok Természettudományi Sorozat 7: 217-240.

[13] NógrÁdI, S., Uherkovich, Á. 1994: The Trichoptera of Balaton and its catchment area. A Janus Pannonius Múz. Évk. 38 (1993): 27-45.

[14] NóGrÁdr S., Uherkovich Á. 1995: A Dráva magyarországi szakaszának tegzes (Trichoptera) faunája. Dunántúli Dolgozatok Természettudományi Sorozat 8: 117-137.

[15] Nógrádi S., Uherkovich Á. 1998a: A Dráva magyarországi szakaszának tegzes (Trichoptera faunáia), II. Dunántúli Dolgozatok Természettudományi Sorozat 9: 331-358.

[16] NógrádI S., Uherkovich Á. 1998b: Protedcted and threatened caddisflies (Trichoptera) of Hungary. Proc. of the 9th Int. Symp. Trichoptera, p. 29I-297. Faculty of Science, University of Chiang Mai, Thailand.

[17] NógrádI, S., UjHelY1, S., Uherkovich, Á. 1985: Fundamental faunistic data on caddisflies (Trichoptera) of South Transdanubia, Hungary. A Janus Pannonius Múz. Évk. 29 (1984): 37-48.

[18] Uherkovich, Á., NógrádI, S. U. 1989: Provisional check-list of the Hungarian Trichoptera. Proceedings of the 6th International Symposium on Trichoptera, Lódz - Zakopane, 1989, p. 247-253. [1992]

[19] Uherkovich, Á., NóGrÁdI, S. 1992: Some data to the Trichoptera fauna of Drava river, Hungary. - Somogyi Múz. Közl. 9: 269-278.

[20] Uherkovich, Á., NógrádI, S. 1997: Platyphylax frauenfeldi Brauer, 1857 (Trichoptera, Limnephilidae) in Hungary. - Braueria 24: 13-14.

[21] UhERKOVICH, Á., NóGRÁDI, S. 1998: The survey of caddisflies (Trichoptera) of the Hungarian catchment area of Dráva river. - Proc. of the 9th Int. Symp. Trichoptera, p. 415-423. Faculty of Science, University of Chiang Mai, Thailand.

[22] UjHeLYi S. (1971): Adatok a Leptoceridae (Trichoptera) család fajainak magyarországi elterjedéséhez. - Folia ent. hung. 24: 119-137.

[23] UjHelyI S. 1981: Die Grundlagen der Neureopteren-, Mecopteren- und Trichopterenfauna des Naturschutzgebietes von Wacholderheide bei Barcs. - Dunántúli Dolgozatok Természettudományi Sorozal 2: 59-63. 


\title{
Checklist of the Caddisflies (Trichoptera) of Somogy county, Hungary
}

\section{SÁra Nógrádi \& ÁKos UherKovich}

A hundred years ago, only 8 caddisfly species were known from Somogy county as it was published by MOCSÁRY (1900). The fauna was hardly studied during the next seventy years. Authors of this paper went on an exhaustive faunistical collecting work since the early 80 's. (See Literature cited.) Thus 123 species belonging to 16 families were taken in Somogy county. Four species (Hydroptila pulchricornis (Pictet, 1834), Micrasema setiferum (Pictet, 1834), Silo piceus (Brauer, 1857) and Helicopsyche bacescui Orghidan \& Botosaneanu, 1953) of the Hungarian fauna were found only in this county. The sole and ultimate stable world population of Platyphylax frauenfeldi also exists in the county, in the River Dráva, which has the most diverse caddisfly communities of the water bodies of the county. The checklist covers not only the species but also gives an account of literary sources and some unpublished occurrences.

\author{
Authors' address: \\ Dr. Sára NÓGrídI \\ Dr. Ákos UHERKOVICH \\ Natural History Department \\ Janus Pannonius Museum \\ H-760l Pécs \\ P. O. Box 347 . \\ HUNGARY
}

